\title{
Legitimidade de fontes e opinião sobre coronavírus em O Grande Debate
}

\section{Legitimacy of sources and opinion about coronavirus in O Grande Debate Legitimidad de fuentes y opinión sobre coronavirus en O Grande Debate}

\author{
Juliana Costa ${ }^{1, a}$ \\ juliana.costa.jor@gmail.com | https://orcid.org/0000-0002-6268-4634 \\ Kênia Maia ${ }^{1, b}$ \\ kbiamaia@gmail.com | https://orcid.org/0000-0002-0753-7340 \\ ${ }^{1}$ Universidade Federal do Rio Grande do Norte, Departamento de Comunicação. Natal, RN, Brasil. \\ a Mestrado em Comunicação pela Universidade Federal de Pernambuco. \\ b Doutorado em Ciência da Informação e da Comunicação pela Université de Metz.
}

\section{RESUMO}

A partir do tensionamento de conceitos como objetividade e opinião no jornalismo, polarização espetacularizada e abordagem da saúde pelo jornalismo, o artigo reflete sobre a legitimidade das fontes às quais recorrem os participantes de O Grande Debate, da CNN Brasil. Foram observadas 14 edições do quadro, com o registro das estratégias empregadas pelos comentaristas, a fim de identificar os padrões de legitimidade e de legitimação das fontes. Percebemos que foram acionadas fontes oficiais ou documentais e também fontes falsas ou pseudofontes, contribuindo para a equiparação entre opinião, fato e inverdade nos debates sobre o novo coronavírus.

Palavras-chave: Fontes jornalísticas; Opinião; Pandemia; Covid-19; CNN Brasil.

\begin{abstract}
Based on the tension between concepts such as objectivity and opinion in journalism, spectacular polarization and the approach to health by journalism, this article reflects on the legitimacy of the sources to which participants in O Grande Debate, transmitted by CNN Brazil, resort. Fourteen editions of this panel were observed, recording the strategies employed by commentators in order to identify patterns of legitimacy and legitimation of the sources. We could detect that official or documentary sources were exploited, as well as false or pseudo sources, contributing to the equivalence between opinion, fact and untruth in the debates about the new coronavirus.
\end{abstract}

Keywords: Journalistic sources; Opinion; Pandemic; Covid-19; CNN Brazil. 


\section{RESUMEN}

A partir de la tensión de conceptos como la objetividad y la opinión en el periodismo, la polarización espectacular y la manera de plantear la salud por parte del periodismo, este artículo reflexiona sobre la legitimidad de las fuentes a que recurren los participantes de O Grande Debate, de la CNN Brasil. Se observaron catorce ediciones del programa y se registraron las estrategias empleadas por los comentaristas para identificar las configuraciones de legitimidad y de legitimación de las fuentes. Notamos que fueron empleadas fuentes oficiales o documentales, así como fuentes falsas o pseudo-fuentes, contribuyendo a la equiparación entre opinión, hecho y falsedad en los debates sobre el nuevo coronavirus.

Palabras clave: Fuentes periodísticas; Opinión; Pandemia; Covid-19; CNN Brasil.

Concepção e desenho do estudo: Juliana Costa e Kênia Maia.

Aquisição, análise ou interpretação dos dados: Juliana Costa e Kênia Maia.

Redação do manuscrito: Juliana Costa.

Revisão crítica do conteúdo intelectual: Kênia Maia.

Declaração de conflito de interesses: não há.

Fontes de financiamento: não houve.

Considerações éticas: não há.

Agradecimentos/Contribuições adicionais: não há.

Histórico do artigo: submetido: 8 set. 2020 | aceito: 9 dez. 2020 | publicado: 30 jun. 2021.

Apresentação anterior: não há.

Licença CC BY-NC atribuição não comercial. Com essa licença é permitido acessar, baixar (download), copiar, imprimir, compartilhar, reutilizar e distribuir os artigos, desde que para uso não comercial e com a citação da fonte, conferindo os devidos créditos de autoria e menção à Reciis. Nesses casos, nenhuma permissão é necessária por parte dos autores ou dos editores. 


\section{INTRODUÇÃO}

A Covid-19 é uma doença causada pelo novo coronavírus (SARS-CoV-2) cujo espectro clínico varia de infecções assintomáticas a casos graves. Sua transmissão foi inicialmente identificada em dezembro de 2019, na cidade chinesa de Wuhan (BRASIL, 2020). A Organização Mundial de Saúde (OMS) classificou em 11 de março de 2020 a Covid-19 como uma pandemia e, até dia 4 de setembro do mesmo ano, foram registrados 26.171.112 casos confirmados e 865.154 mortes em função da doença em todo o mundo (OPAS, 2020). A gravidade do estado de saúde dos infectados, bem como os altos números de casos e a rápida evolução dos números de leitos ocupados em hospitais num curto espaço de tempo se tornaram fortes ingredientes para reforçar o tratamento do assunto pela mídia a partir de diferentes perspectivas.

Notadamente, veículos jornalísticos se debruçaram sobre o tema e muitas reportagens foram feitas a respeito, apontando prismas diversos do mesmo assunto - o que nos lembra que a prática do jornalismo profissional está calcada em metodologias voltadas para a produção de material jornalístico focado em informação. Ao mesmo tempo em que a busca pela objetividade surge diante do entendimento de que os fatos são subjetivos (PENA, 2012), jornalistas adotam um ritual estratégico na condução de suas atividades, muitas vezes num movimento de proteção contra críticas ao seu trabalho (TUCHMAN, 1993).

Para Miranda (2017), o jornalismo especializado em saúde é dependente de fontes técnicas e especializadas, apoiando-se num saber traduzido como verdade. No contexto pandêmico-midiático provocado pelo novo coronavírus, essas fontes são alçadas a uma posição de relevância e importância para os profissionais e para o público, e "[...] não raras vezes os produtos midiáticos buscam confrontá-las a fim de que se promovam certezas [...]” (MIRANDA, 2017, p. 5).

Tal reflexão nos remete, portanto, à necessidade de realização de uma cuidadosa observação dos fenômenos comunicativos - especialmente aqueles envolvidos no manejo da informação científica inserida no circuito jornalístico. Por um lado, a posição e a abordagem das fontes no tratamento de temas científicos e/ou ligados à área da saúde termina por refletir um quadro significativo de referências e credibilidade. Pretensamente, não haveria espaço para interpretações que ultrapassassem os limites estabelecidos pela informação fornecida por fontes especializadas. Porém, o mencionado quadro da CNN alarga a discussão sobre o tratamento da informação científica por seus diferentes divulgadores. A pandemia causada pelo novo coronavírus, por sua vez, potencializa fenômenos comunicativos, não sendo apenas o cenário mas também o fator gerador de movimentos que demandam um olhar analítico capaz de perceber as marcas pandêmicas deixadas no manejo da informação científica.

Num cenário em que a busca de mais informações demanda fontes a todo o momento, tivemos nossa inquietação despertada pelos cenários de opinião sobre a pandemia, ponto ambíguo no que se refere à legitimidade de tais fontes, já que diferentes pontos de vista são apresentados em igualdade de condições para o público. Desse modo, chegamos à nossa pergunta-problema: as fontes que servem de base para as opiniões veiculadas sobre o tema obedecem aos mesmos critérios delegitimidade? Responder a essa pergunta é importante para poder indicar se argumentos técnicos são suplantados pelo valor da exposição midiática, ou melhor, pelo valor da espetacularização midiática, francamente apoiada na polarização de posições. Outra contribuição do trabalho aqui apresentado está na percepção de uma eventual dinâmica exercitada na abordagem da saúde pela opinião no jornalismo. Por último, o trabalho empreendido neste sentido se debruça sobre a análise de um espectro específico da comunicação sobre a saúde, centrada na perspectiva desenvolvida a partir de fontes de informações como ponto de reflexão sobre potências e consequências de sua legitimidade num contexto de abordagens técnico-científicas sobre o novo coronavírus.

A fim de refletir sobre essa dinâmica possível e esboçar uma análise sobre a sua ocorrência ou não, o presente trabalho se debruça sobre 14 edições do quadro O Grande Debate, exibido pela CNN Brasil. Nosso 
objetivo neste artigo é, partindo de um estudo empírico e qualitativo, verificar se as fontes nas quais os debatedores se baseiam possuem sustentação técnica ou científica nos debates que se referem à pandemia provocada pelo novo coronavírus, incluindo aí as discussões sobre contágio, controle e eventual cura para a Covid-19.

Entendemos ser necessário refletir antes sobre alguns pressupostos que fundamentam nossa discussão. Iniciaremos essa jornada considerando as fontes de informação e o seu papel para a prática jornalística.

\section{FONTES E INFORMAÇÃO ESPECÍFICA}

O conceito dicionarizado de fonte, passível de uma simplificação generalizada para sua indicação como origem da informação, pode pecar por não apontar imediatamente a complexidade de suas tipologias possíveis ou cenários viáveis para a reflexão e análise de sua atuação, mas nos aponta indícios para a compreensão de seu papel fundamental na prática jornalística e de sua relevância para o produto jornalístico final a ser obtido.

Diz Neveu (2006) que as fontes são fundamentalmente ativas - e o jornalista, consequentemente, se encontra imerso num mar de informações. Não por acaso, Alsina (2009) eleva as fontes ao patamar de grande importância para a compreensão tanto do processo produtivo da notícia quanto do estudo do profissionalismo jornalístico, apontando o elo existente no tripé acontecimento-fonte-notícia como básico para a construção da realidade jornalística.

Para Pena (2012), o surgimento do jornalismo tem ligação direta com nosso medo do desconhecido e consequente anseio pela ubiquidade. É neste ponto que o papel das fontes de informação ganha, para a prática jornalística, a importância fundamental de possibilitar ao leitor/ouvinte/espectador saber o que se passa em diferentes espaços, conforme o assunto que lhe interessa e a perspectiva que melhor lhe atenda.

Pensar sobre fontes de informação para o ofício jornalístico, todavia, nos permite perceber reflexões empreendidas sobre dois tipos de contribuições principais: uma concentrada em garantir uma consideração taxonômica das fontes propriamente ditas; e outra preocupada em refletir sobre as estratégias e ambientes contemplados por elas que são parte fundamental para a difusão de informações em veículos jornalísticos. Esses dois tipos de contribuição não excluem um ao outro, mas se complementam em seus apontamentos a fim de salientar o ponto a partir do qual desenvolveremos nossa reflexão neste artigo.

Trabalhos como os de Erbolato (2008), Lage (2005) e Pinto (2000) nos apresentam tipos de fontes e indicam características que definem cada uma. Em todos os casos, a fonte é entendida como tal, conforme sua ligação com o tema tratado e sua posição no desenho hierárquico do complexo orgânico da construção da possível notícia. Essas reflexões compartilham ainda entre si uma preocupação (declarada ou subentendida) em orientar o repórter na abordagem e/ou utilização das informações fornecidas pelas fontes, municiando-o de um entendimento a respeito de suas considerações sobre a valorização de cada tipo, conforme as circunstâncias e o foco da notícia propriamente pretendida.

Por outro lado, os trabalhos que voltam sua atenção para as estratégias e os ambientes, respectivamente, empregadas e ocupados pelas fontes, nos trazem uma perspectiva de ação, abraçando a premissa de fontes múltiplas e ativas de que falava Neveu (2006), e fora do imaginário de um jornalismo romântico e idealizado, no qual apenas o jornalista vai em busca de seus informantes. Chaparro $(1994,2014)$ descreve uma revolução das fontes, capacitadas e inseridas num circuito adaptado ao modus operandi da própria mídia, enquanto Schmitz (2011) aponta o detalhamento das ferramentas abraçadas como dispositivos de inserção das fontes e suas informações (versões), num fortalecimento de narrativas construídas conforme interesses - não apenas do público, mas também do veículo jornalístico e da própria fonte.

Como já dissemos anteriormente, entendemos que os dois caminhos reflexivos mencionados trazem contribuições complementares. Isso porque o contato estabelecido entre jornalista e fonte está permeado 
essencialmente tanto pela percepção do tipo de fonte (e, consequentemente, por seu valor subentendido na produção da notícia, conforme sua ligação com a informação) quanto pelos caminhos relacionais percorridos pela fonte (considerados aí o jornalista, o veículo jornalístico e o produto jornalístico resultante). Tais reflexões se tornaram ainda mais relevantes num cenário em que se lida com circunstâncias de necessidade de informação específica e/ou especializada, uma vez que o ponto que, acreditamos, é comum às duas linhas de abordagem é o papel desempenhado pela fonte no material jornalístico produzido.

Se considerarmos que

as fontes são pessoas, são grupos, são instituições sociais ou são vestígios - falas, documentos, dados - por aqueles preparados, construídos, deixados. As fontes remetem para posições e relações sociais, para interesses e pontos de vista, para quadros espáciotemporalmente situados (PINTO, 2000, p. 278),

admitimos que elas carregam em si não apenas um ponto original (ou semioriginal) de informação, mas também um valor de legitimidade para a informação e para a própria notícia. Quanto mais específica é essa fonte, ou melhor, se responde por determinada instância de uma organização, se detém resultados de pesquisas científicas, se está à frente de uma operação policial ou de uma demanda jurídica, mais o jornalista a entende como específica e mais ela pode agregar ao resultado final pretendido.

As fontes podem se mostrar como parte da estratégia do jornalista científico a fim de, conforme afirmam Maia e Gomes (2006), fornecer informações capazes de esclarecer conceitos, teorias e noções importantes para a sociedade e exercer sua função de elo entre a sociedade e a ciência. Explicam-nos Mega e Silva (2019) que, no contexto do jornalismo científico (seja na área de saúde, tecnologia ou meio ambiente), o jornalista deve não apenas ouvir pesquisadores, como trazer novas fontes e criar debates mais amplos sobre o tema tratado. Não por acaso, Miranda (2017) salienta que o jornalismo especializado em saúde tem uma dependência característica de fontes especialistas, que é "uma dependência do seu saber e do poder que dele deriva." (MIRANDA, 2017, p. 8)

Direta ou indiretamente, as ponderações de Miranda (2017), de Maia e Gomes (2006) e de Mega e Silva (2019) nos conduzem ao reconhecimento da fonte enquanto item essencial para o manejo da informação científica, uma vez que ela se mostra como integrante de fenômeno comunicativo que caracteriza a prática jornalística em sua essência aliada à necessidade de ampliação do escopo de abordagem e/ou tradução da linguagem específica ligadas à especificidade do tema abordado.

Ao contar com uma ou várias fontes, a notícia/reportagem intenta ter seu conteúdo referendado: há um testemunho, uma indicação, um respaldo que não apenas aponta para o fato como real, mas também uma legitimação da notícia, reforçada pela legitimidade da fonte. É Foucault (2009) quem nos dá a pista de que precisamos para refletir sobre este ponto. O filósofo francês explica que a produção do discurso opera três sistemas de exclusão: a interdição, a segregação e a vontade de verdade - este, que retoma constantemente os dois primeiros, é apoiado sobre um suporte e uma distribuição institucionais, capazes de exercerem sobre os discursos um tipo de pressão e de poder coercitivo, de modo que "a vontade de verdade é reconduzida, mas profundamente sem dúvida, pelo modo como o saber é aplicado em uma sociedade, como é valorizado, distribuído, repartido e de certo modo atribuído" (FOUCAULT, 2009, p. 17).

Não por acaso, Resende (2014) aponta a mídia como uma instância legitimadora de falas que se atribuem como verdadeiras: é reguladora e mantenedora do que ele aponta como sendo um status quo cujo objetivo central é a ordenação dos fatos que permeiam as relações sociais dos indivíduos. Sobre este ponto, o autor reforça:

Sua chegada, com tamanha força e rapidez, nos faz defrontar como fato de que cada discurso, a seu modo, em concomitância, que se apresentar mais verdadeiro que o outro. Ambas as falas ancoram-se, com veemência, na suposta legitimidade tanto do sujeito 
falante como do lugar de onde se fala. E desse modo, a simultaneidade de exposição desses dizeres, que nos chegam através dos discursos da mídia, é fundamental para entendermos que o embate alcança o seu extremo, reduzindo o discurso à sua vontade de verdade, procedimento que se exacerba a partir da luta pela ocupação do espaço midiático. (RESENDE, 2014, p. 214)

Diante dessa tomada de posição, colocamos a mesma preocupação de Leal e Carvalho (2015), ao indicarem a recorrência de enquadramentos em suas pesquisas: nos depararmos com o enigma que nos obriga a pensar sobre a origem da fonte, sua percepção das informações que compartilha e as tensões que se fazem presentes em cada uma são uma consequência da preocupação a respeito da interpretação do que se entende como fonte jornalística. Essa preocupação ganha um caráter especial ao considerarmos o contexto de nossa contemporaneidade: a multiplicidade de informações, discrepantes e em disputa entre si, convive ora pacífica, ora conflituosamente, com fake news e pluralidade de versões.

Por fim, parece-nos fundamental compreender a complexidade das condições em que a fonte de informação se encontra na prática jornalística e suas implicações, ponto sobre o qual discorreremos no próximo tópico.

\section{OBJETIVIDADE, OPINIÃO E PRÁTICA JORNALÍSTICA: CIRCUNSTÂNCIAS, VARIANTES E POSSIBILIDADES}

O cotidiano do jornalista está, essencialmente, calcado em rotinas vivenciadas pelos profissionais na execução de suas atividades. Essas rotinas, por seu turno, seguem uma ligação orgânica com três bases fundamentais para sua realização: a posição dos jornalistas para as atividades em questão, o produto jornalístico pretendido (que considera formato, periodicidade e público a ser contemplado) e as diretrizes pelas quais a organização jornalística se orienta (sejam documentais e/ou ético-morais). Por isso, para cumprir nossa reflexão inicial, parece-nos fundamental resgatar uma discussão sobre o papel da objetividade nas redações.

Para Tuchman (1993), a objetividade está presente no cotidiano do jornalista tal qual um ritual estratégico, que municia o profissional com ferramentas capazes de poupá-lo de críticas, constrangimentos organizacionais e interorganizacionais, problemas jurídicos e afins. Não por acaso, Pena (2012) salienta que a objetividade não deve ser entendida como o oposto da subjetividade, mas sim como o reconhecimento da inevitabilidade da segunda, estando por isso vinculada a uma metodologia de trabalho. $\mathrm{O}$ autor ressalta que o método, sim, seria objetivo e fonte de uma espécie de margem de segurança da qual o jornalista poderia se valer, a fim de garantir que sua subjetividade pessoal não interferisse na condução de sua atividade.

Num esforço para refinar ainda mais a reflexão sobre o tema, pesquisas como a desenvolvida por Sponholz (2008), mesmo ressaltando a compreensão múltipla do conceito de objetividade por parte dos próprios profissionais (havendo a possibilidade deles a entenderem como mais de uma noção associada entre si, tais como investigação, relevância ou equilíbrio), apontam que a maior parte deles a associa imediatamente à ideia de neutralidade. Por outro lado, ao mesmo tempo em que afirma ser a objetividade um valor assumido pelos profissionais (e veículos jornalísticos) autodenominados imparciais e comprometidos apenas com a verdade dos fatos, Fernandes (2016) aponta o que considera uma insuficiência do conceito de objetividade para abraçar a complexidade de uma prática jornalística voltada exclusivamente para a reprodução dos fatos da realidade - algo não ignorado nem mesmo pelos próprios jornalistas. Conforme o autor, a despeito das críticas levadas a cabo em âmbito teórico, “o princípio da objetividade continua sendo adotado como fundamento da prática jornalística, embora os(as) próprios(as) jornalistas reconheçam a 'utopia' em que consiste a busca da objetividade" (FERNANDES, 2016, p. 147). 
Tais constatações reforçam o posicionamento de Pena (2012) sobre a dissociação frequente, no contexto brasileiro, entre informação e opinião como um critério de objetividade. Mais uma vez, aqui é fundamental retomar a função da metodologia de trabalho jornalístico, devidamente adequada não apenas a questões estratégicas como as apontadas por Tuchman (1993), mas também ao produto jornalístico pretendido: se é uma reportagem para uma revista, para uma rádio ou para um programa de televisão, por exemplo. Nesse cenário, é importante lembrar que a metodologia do trabalho jornalístico acaba sendo acompanhada por documentos formais ou informais que cumprem uma função regulatória, tanto local quanto globalmente. São ocupantes desse lugar os manuais da redação, as cartas de recomendação e declaração de princípios das organizações jornalísticas e o Código de Ética da profissão, além da própria legislação que trata sobre o exercício da atividade.

O caso da opinião no jornalismo, por outro lado, acaba nos apontando um caminho fértil em potencialidades e provocações para a chamada objetividade - seja ela entendida como sinônimo de imparcialidade, ou como um valor profissional exercitado pelos jornalistas. A diversidade de gêneros e formatos se choca diretamente contra as saídas encontradas pelos veículos jornalísticos a fim de manterem um movimento duplamente ambíguo e contraditório. Ao mesmo tempo em que alardeiam a pluralidade de opiniões e/ou perspectivas que encontram abrigo sob seu espaço, recorrem a frases ditas por apresentadores ou grafadas em letras menores, abaixo do texto em questão, em que ressaltam que as opiniões emitidas naquele espaço não refletem, necessariamente, a posição do veículo.

A preocupação com os estudos sobre gêneros jornalísticos, tais como os empreendidos por Marques de Melo (2003, 2010) e Marques de Melo e Assis (2016), nos mostra o cuidado reflexivo com os espaços destinados à opinião nos veículos jornalísticos: seja ela emitida por jornalistas, artistas, políticos, especialistas em determinado assunto ou mesmo leitores/telespectadores, entre tantas possibilidades, considerando os formatos e potencialidades. Ao mesmo tempo, ressaltamos que as possibilidades de manifestação de opinião na imprensa também tomam como pressuposto (subentendido ou não) o respeito à objetividade entendida como neutralidade: com exceção de casos como, por exemplo, o editorial, espaço abertamente reservado para a manifestação opinativa da empresa jornalística, as manifestações sobre temas diversos acontecem sem a chancela explícita de um porta-voz da empresa que veicula sua expressão.

Freitas e Pires (2009) afirmam a impossibilidade de encaminhar uma reflexão sobre o que os autores apontam como opinião jornalística, considerando para isso apenas os espaços destinados exclusivamente a ela; não por acaso, os autores adotam a expressão opinião jornalística em oposição a termos como jornalismo de opinião e jornalismo opinativo, sob o argumento de que a opinião está presente no jornalismo independentemente de seu formato e grau de explicitação. Concordamos em parte com os autores, por entendermos que, ao mesmo tempo em que a opinião perpassa sim todo o jornalismo, se faz necessário considerar a demarcação estabelecida pelos próprios veículos jornalísticos para os espaços pretensamente exclusivos para a opinião, por serem um indicativo de tratamento/condução pública da opinião nos veículos e nesses espaços. Por isso, preferimos adotar a expressão opinião no jornalismo, em detrimento das demais já citadas.

Salientamos que, independentemente do foco, o jornalismo necessariamente esbarrará numa condição primeira de sua ação: a clareza de seu conteúdo, materializada na linguagem empregada e compreensibilidade pretendida diante da diversidade de seu público, mergulhada no contexto dos temas sobre os quais irá tratar. É fundamental destacarmos que,

Neste contexto, 'objetividade' tem uma função ambivalente. Pode tanto promover integração, no sentido de que até mesmo um semianalfabeto possa receber e processar as informações, ou exclusão, quando certos temas deixam de ser tratados, porque o homem comum supostamente não teria condições de entendê-los. (SPONHOLZ, 2008, p. 75) 
Ao mesmo tempo que concordamos com Sponholz (2008), percebendo uma visão profissional elitista nessa condição para escolha e tratamento dos temas, também entendemos a necessidade de um tratamento cuidadoso do produto jornalístico que, sendo simples, não seja simplório. Nossa perspectiva neste trabalho é de que, ao mesmo tempo que a opinião no jornalismo não o isenta de questões como a apuração, ela bifurca o caminho trilhado pelo veículo jornalístico e o emissor de opinião - esse último porta-voz de fontes eventualmente não checadas pelos demais jornalistas -, alterna sua posição com a fonte, conferindo níveis de legitimidade para a opinião que não são, necessariamente, originados de uma mesma condição.

Aqui, retomamos a perspectiva de Tuchman (1993) e as estratégias empregadas pelos jornalistas: ao apontar a apresentação de possibilidades conflituais, a apresentação de provas auxiliares, o uso judicioso das aspas e a estruturação da informação numa sequência apropriada, a autora abre caminho para o que salientamos como a percepção crítica da responsabilização das fontes nas apurações feitas pelos jornalistas. O ponto para o qual atentamos aqui, claramente, não é aquele em que Tuchman (1993) ressalta o movimento de preservação dos jornalistas diante de potenciais constrangimentos organizacionais e problemas jurídicos, mas sim sua consequência. As fontes passam a significar, para o jornalista e para o público, a garantia de legitimidade necessária para a veiculação da informação - assumindo, consequentemente, a carga de responsabilidade pela veracidade: se a fonte diz, pretensamente, é porque de fato aconteceu.

Neste ponto, merecem especial atenção as fake news. Para Carvalho (2019), elas implicam uma discussão epistemológica: enquanto o produto jornalístico deve ser pautado pela realidade, as fake news invertem essa conduta e rompem com um compromisso com a verdade, facilitado e potencializado no ambiente da internet e das redes sociais. Jorge (2017), considera que a notícia é um organismo vivo e sujeito a mutações em seu estado, composição, propriedades e energia, e aponta que as fake news são caracterizadas pelo conteúdo propositadamente enganoso que, a fim de influenciar pessoas, se apresenta com o formato de notícia. Seguindo a perspectiva de Paula, Silva e Blanco (2018), entendemos que o ponto comum está, assim, na implicação de sua intencionalidade, já que, como afirmam esses autores, "Elas podem ser consideradas conteúdos que buscam evocar os sentimentos do leitor e com frequência fabricar uma revolta relativa à entidade/pessoa que está sendo deslegitimada" (PAULA; SILVA; BLANCO, 2018, p. 96), além de terem a possibilidade de "apresentar uma narrativa unilateral para fomentar as opiniões, 'fatos' e pontos de vista apresentados no texto" (PAULA; SILVA; BLANCO, 2018, p. 96), tornando ainda mais potencialmente delicada a condição do profissional que lida com a emissão de opinião no jornalismo e a referência a uma fonte não checada.

Diante do que nos propomos a analisar aqui, torna-se necessário passar para uma outra instância de provocação: a legitimidade das fontes invocadas num cenário de polarização de opiniões.

\section{POLARIZAÇÃO DE OPINIÕES E LEGITIMIDADE DAS FONTES}

A polarização (aqui entendida como uma diferença irreconciliável entre dois polos, que podem ser opinativos, deliberativos ou consultivos) de posicionamentos ganhou especial destaque no cenário comunicacional brasileiro graças, fortemente, ao embate sobre temas políticos, envolto também nas complexidades que as redes digitais e a proliferação de fake news impulsionaram no contexto dos últimos anos (MIGUEL, 2019). Naturalmente, opiniões e/ou posicionamentos polarizados impõem a necessidade de refletir sobre o papel da mídia para seu efeito, de modo que trabalhos, como o desenvolvido por Melki e Pickering (2014), já concluíram que um maior consumo de informação transmitido pela mídia conduz a um maior acordo político, numa complementação às reflexões sobre a relação entre polarização e acesso à informação divulgada nos meios de comunicação e contrariando a ideia de que a polarização se acentua pelo excesso de informações publicamente compartilhadas. 
Concentrando nossa reflexão no jornalismo especializado em saúde, consideramos questões específicas a ele - são elas que tornarão possível a percepção de potenciais efeitos de uma polarização de opiniões no seio de seu exercício. Nesse ínterim, Kuscinsky (2002) enfatiza que há nesse tipo de jornalismo "uma ideologia do não conhecimento" (p. 99); enquanto Miranda (2017) ressalta que o jornalismo especializado em saúde é capaz de "evidenciar enunciados de verdade, escondendo ou camuflando mecanismos de poder que emanam do saber médico [...]" (MIRANDA, 2017, p. 8). Saint Clair (2012) reforça a possibilidade de produção de matérias que, em seu conjunto, não estejam comprometidas com uma única verdade científica, mas endossem acriticamente uma pesquisa/perspectiva momentânea como verdade.

A perspectiva de Miguel (2019) reforça que o principal efeito ideológico do jornalismo é passar a noção de que o conhecimento singular produzido por ele é o conhecimento necessário para a vida social naquele momento. Segundo esse autor:

Trata-se, portanto, de uma disputa pela posição de gatekeeper legítimo. Os novos agentes adotam como discurso a denúncia do alinhamento do campo jornalístico como uma posição (à esquerda ou à direita, dependendo do caso) e assumem a posição de desveladores de uma realidade oculta. O jornalismo, como revide, reforça em seu discurso o apego aos valores profissionais de objetividade, respeito à verdade factual e isolamento estrito entre notícia e opinião. (MIGUEL, 2019, p. 50)

Nossa perspectiva é de que o isolamento a que o autor se refere é potencial mola propulsora para um espaço espetacularizado para o jornalismo, que ora se alimenta desses valores profissionais, ora se apoia nas condições organizacionais dos próprios veículos para ajustar e se aproveitar desses espaços de polarização. Nos apoiamos aqui nas contribuições de Debord (2005) sobre as características de uma sociedade do espetáculo: a relação estabelecida entre as pessoas, voltada para a recepção do espetáculo, é uma espécie de transformação do real, na qual importa mais ter do que ser. E mais: importa mais parecer ter do que, propriamente, ter. Concordamos com Kuscinsky (2002) e sua percepção de que o exercício do jornalismo especializado em saúde é afetado por fenômenos como a espetacularização, reducionismo e elitismo temático, além de refletir abordagens de mercantilização da notícia e da própria saúde, concentrando-se apenas nas manifestações de tais processos. Desse modo, podemos indicar que a polarização constitui o espetáculo, garantindo uma percepção necessariamente incompleta e restrita da questão considerada. Essa perspectiva mostra-se especialmente interessante ao considerarmos o eventual papel das fontes nesse contexto.

Hall, Chritcher, Jefferson, Clarke e Roberts (1993), ao falarem sobre os definidores primários (fontes acreditadas, porta-vozes institucionais que ressoam pontos de vista dos poderosos, ou detentores dos meios de produção, numa terminologia mais próxima do marxismo), salientaram que a relação estabelecida entre os definidores primários e a mídia permitia estabelecer a interpretação, ou mesmo definição primária do tópico em questão. Numa perspectiva de polarização como espaço espetacularizado e veiculado midiaticamente, como resultado, acontece que "os argumentos contrários a uma interpretação primária são obrigados a inserirem-se na sua definição de 'o que está em questão' - devem ter como seu ponto inicial esta estrutura de interpretação" (HALL et al., 1993, p. 230).

Nossa perspectiva é de que esse cenário que acaba por favorecer o que Freitas e Pires (2009) ressaltaram como a diferença entre a opinião publicada e a opinião pública, deslocamento que provoca, entre outras consequências, a "radicalização opinativa nos espaços e autores das 'opiniões publicadas', que passam a manter opiniões com a aparência de jornalísticas, mesmo quando as tradicionais apurações jornalísticas não as confirmam ou, por vezes, mesmo as desmentem" (FREITAS; PIRES, 2009, p. 140).

Entendemos, portanto, que a fonte jornalística se localiza como ponto fundamental para a compreensão do fenômeno da polarização, demandando por isso a verificação de sua legitimidade para que se torne 
possível uma análise do manejo da informação científica e sua conjuntura, capaz de interferir nos processos e potenciais efeitos deste recorte do fenômeno da comunicação em saúde.

Considerando a espetacularização midiática no contexto de polarização, poucos momentos de embate são tão lembrados, no cenário brasileiro, quanto os debates entre os candidatos a cargos públicos durante os períodos de campanha eleitoral. A cada dois anos, a fim de contemplar tanto eleições nacionais quanto estaduais e municipais, veículos de comunicação promovem o encontro dos candidatos, convidados a expor seus pontos de vista e propostas para diferentes temas, obedecendo a uma metodologia específica: uma mesma pergunta para todos, sorteio entre os candidatos para fazerem perguntas entre si e tempo estipulado para pergunta ou resposta, réplica e tréplica. Casos como o ocorrido em 1989, no debate entre os então candidatos à presidência da República, Fernando Collor de Melo e Luiz Inácio Lula da Silva, são lembrados à exaustão para ilustrar o peso da edição no resultado final exibido ao público.

Nesse aspecto, e considerando nossa proposta de trabalho, pensar na espetacularização e associá-la à opinião no jornalismo que aborda a saúde implica necessariamente refletir sobre as bases que sustentam a polarização das opiniões num cenário midiático. Ao nos concentrarmos no formato de um debate dentro de um programa jornalístico, e tendo sido escolhido o tema a ser objeto do debate (resultado de um contexto sociomidiático determinante), encontramos aí três eixos fundamentais a serem considerados: 1) formato; 2) metodologia de trabalho; e 3) partes envolvidas.

O primeiro eixo, formato, nos permite delinear as condições de exposição: espaço de inserção, disposição espacial e/ou visual das partes envolvidas e tempo de exposição. No segundo eixo, metodologia de trabalho, temos a oportunidade de traçar o roteiro seguido: indicação do tema, apresentação das partes envolvidas e condução da discussão. Por fim, no terceiro eixo, partes envolvidas, podemos observar os argumentos utilizados para a defesa de suas opiniões, bem como para discordância dos pontos apresentados pelo debatedor oposto.

A partir das contribuições de Foucault (2009) e Resende (2014), entendemos que o cenário idealizado para esse tipo de circunstância apontaria que os comentaristas/debatedores buscam, a fim de validar suas posições no embate, legitimar suas colocações a partir de dados e/ou argumentos obtidos por meio de fontes. No entanto, o aspecto da espetacularização amplia as possibilidades circunstanciais, indicando um potencial deslocamento de peso da legitimidade da fonte, secundarizada, para a exploração gratuita da diferença opinativa. Neste caso, perde força o argumento da objetividade jornalística e ganha espaço o foco na audiência entretida com a oposição de opiniões potencialmente não fundamentadas (o que significaria a implosão de aspectos próprios da rotina produtiva jornalística, como apuração e pesquisa, por exemplo).

Feitas tais apreciações, vamos agora às considerações e detalhamento sobre o objeto de nossa análise.

\section{CORONAVÍRUS EM O GRANDE DEBATE}

Ramificação do canal homônimo norte-americano, a CNN Brasil iniciou suas transmissões em território brasileiro em 15 de março de 2020, com a proposta de ser um canal focado essencialmente em jornalismo, multiplataforma (é possível conferir as produções do canal no Twitter, no Instagram, no Facebook e no YouTube, além de plataformas de podcast e site oficial) e acessível através de operadoras de televisão por assinatura. Conforme o site oficial do canal, seu conselho editorial é presidido por Douglas Tavolaro e formado por sete jornalistas e um advogado com especialização na área de mídia e comunicação. É esse conselho que responde pelos conteúdos veiculados e pela definição de política e parâmetros editoriais. O grupo declara, entre suas atribuições, zelar pelo News Standards \& Practice Guide da CNN (um equivalente aos manuais da redação), além de definir a política e os padrões editoriais (CNN BRASIL, 2020).

$\mathrm{O}$ quadro sobre o qual nos debruçamos, O Grande Debate, repete a fórmula do quadro original e homônimo americano e passou a ser exibido diariamente desde o dia 16 de março de 2020, dentro do 
telejornal CNN Novo Dia, que vai ao ar às 6h. A partir do dia 06 de abril do mesmo ano, o quadro passa a ocupar também um espaço no programa Expresso CNN, exibido às 18h3o. Entre os dias 16 de março e 31 de julho de 2020 foram exibidos 180 debates, sempre de segunda a sexta-feira e com tempo de duração irregular: o mais curto, ocorrido no dia 18 de março, durou 20 minutos e 35 segundos; o mais longo, exibido no dia 21 de abril, teve duração total de uma hora, dez minutos e 27 segundos. O formato permanente comporta a presença de dois debatedores e um mediador (ladeado pelos dois comentaristas tanto na bancada, no estúdio, quanto nas edições de vídeo), funções cujos ocupantes sofrem alternância, conforme as edições dos debates acontecem no decorrer dos dias.

O formato é simples: diante de um tema escolhido, invariavelmente algo que tenha ganhado força no noticiário nacional e tenha sido explorado também pela própria emissora, dois comentaristas são convidados a defender seus pontos de vista (divergentes entre si) sobre o ponto discutido. O mediador, além de indicar para os telespectadores o tema a ser debatido, também aponta para os comentaristas os pontos que serão discutidos em cada bloco. Transmitido ao vivo, O Grande Debate também tem todas as suas edições disponibilizadas no canal oficial da CNN Brasil no YouTube, espaço de onde extraímos nosso corpus para a análise.

O roteiro é repetido, a partir de então, no começo do quadro em todas as suas exibições: o mediador exalta a importância do quadro, salientando que se trata de um sucesso americano e que se repete com êxito no Brasil; reforça que é constituído pela exposição de opiniões diferentes para que o telespectador possa construir a sua própria opinião; fala sobre o tema, que esteve entre as notícias exibidas no dia, introduzindo-o brevemente; apresenta os debatedores, indicando as credenciais de cada um (grau de escolaridade ou título acadêmico e ocupação profissional); e dá início ao espaço de exposição dos argumentos.

Partindo do recorte de tempo estabelecido (entre 16 de março e 31 de julho de 2020), fizemos uma préindicação entre os 180 debates realizados, utilizando como critério de seleção que seus temas dialogassem direta ou indiretamente com a pandemia ocasionada pelo novo coronavírus no Brasil, considerando não só o foco sanitário mas também econômico, político e social na indicação do tema explicitada pelo próprio canal em cada um dos vídeos em questão. Nesta etapa, chegamos a 31 vídeos. A partir daí, iniciamos uma segunda fase de seleção, considerando o conjunto obtido anteriormente e estabelecendo como critério que, no conteúdo de cada um dos debates, fossem abordadas questões referentes à infecção pelo novo coronavírus, bem como a Covid-19 e seus efeitos. Neste caso, chegamos a 14 vídeos, que dividimos em duas categorias amplas: a primeira, tratamento e cura; a segunda, controle social, conforme é possível observar a seguir.

Quadro 1 - Vídeos selecionados | Categoria tratamento e cura

\begin{tabular}{|l|l|l|l|l|}
\hline Dia & Tema & Duração & Mediador(a) & Debatedores \\
\hline 19.03.2020 & Medidas contra a Covid-19 & $37^{\prime} 35^{\prime \prime}$ & Reinaldo Gottino & $\begin{array}{l}\text { Gabriela Prioli e Tomé } \\
\text { Abduch }\end{array}$ \\
\hline 07.04.2020 & $\begin{array}{l}\text { Brasil deve usar droga polêmica no } \\
\text { combate à Covid-19? }\end{array}$ & $37^{\prime} 37^{\prime \prime}$ & $\begin{array}{l}\text { Monalisa } \\
\text { Perrone }\end{array}$ & $\begin{array}{l}\text { Caio Coppolla e Augusto } \\
\text { de Arruda Botelho }\end{array}$ \\
\hline 21.05.2020 & $\begin{array}{l}\text { Uso da cloroquina é protocolo ou } \\
\text { orientação? }\end{array}$ & $55^{\prime} 28^{\prime \prime}$ & Reinaldo Gottino & $\begin{array}{l}\text { Gisele Soares e Thiago } \\
\text { Anastácio }\end{array}$ \\
\hline
\end{tabular}

Fonte: elaboração das autoras.

\section{Quadro 2 - Vídeos selecionados | Categoria controle social}




\begin{tabular}{|c|c|c|c|c|}
\hline Dia & Tema & Duração & Mediador(a) & Debatedores \\
\hline 20.03.2020 & $\begin{array}{l}\text { Coronavírus: Liberdade para os } \\
\text { presos }\end{array}$ & $40 \prime 36 "$ & Reinaldo Gottino & $\begin{array}{l}\text { Gabriela Prioli e Tomé } \\
\text { Abduch }\end{array}$ \\
\hline 26.03.2020 & $\begin{array}{l}\text { Prioli e Abduch falam sobre o } \\
\text { isolamento vertical }\end{array}$ & $41^{\prime} 48^{\prime \prime}$ & Reinaldo Gottino & $\begin{array}{l}\text { Gabriela Prioli e Tomé } \\
\text { Abduch }\end{array}$ \\
\hline 14.04 .2020 & $\begin{array}{l}\text { Monitorar celular é invasão ou } \\
\text { defesa contra vírus? }\end{array}$ & $40^{\prime} 03^{\prime \prime}$ & $\begin{array}{l}\text { Monalisa } \\
\text { Perrone }\end{array}$ & $\begin{array}{l}\text { Caio Coppolla e Augusto } \\
\text { de Arruda Botelho }\end{array}$ \\
\hline 17.04.2020 & $\begin{array}{l}\text { São Paulo deveria ampliar a } \\
\text { quarentena? }\end{array}$ & $39 ' 32^{\prime \prime}$ & $\begin{array}{l}\text { Monalisa } \\
\text { Perrone }\end{array}$ & $\begin{array}{l}\text { Caio Coppolla e Augusto } \\
\text { de Arruda Botelho }\end{array}$ \\
\hline 04.05 .2020 & $\begin{array}{l}\text { O estado de SP está certo ao } \\
\text { obrigar o uso de máscaras? }\end{array}$ & $36^{\prime} 29^{\prime \prime}$ & $\begin{array}{l}\text { Monalisa } \\
\text { Perrone }\end{array}$ & $\begin{array}{l}\text { Caio Coppolla e Augusto } \\
\text { de Arruda Botelho }\end{array}$ \\
\hline 06.05.2020 & $\begin{array}{l}\text { É hora de fazer lockdown em São } \\
\text { Paulo? }\end{array}$ & $36^{\prime} 59^{\prime \prime}$ & $\begin{array}{l}\text { Monalisa } \\
\text { Perrone }\end{array}$ & $\begin{array}{l}\text { Caio Coppolla e Augusto } \\
\text { de Arruda Botelho }\end{array}$ \\
\hline 19.05.2020 & $\begin{array}{l}\text { Feriado fora de época ajuda no } \\
\text { combate ao coronavírus? }\end{array}$ & $35^{\prime} 55^{\prime \prime}$ & $\begin{array}{l}\text { Monalisa } \\
\text { Perrone }\end{array}$ & $\begin{array}{l}\text { Caio Coppolla e Augusto } \\
\text { de Arruda Botelho }\end{array}$ \\
\hline 03.06 .2020 & $\begin{array}{l}\text { São Paulo está preparado para } \\
\text { flexibilizar a quarentena? }\end{array}$ & $33^{\prime} 03^{\prime \prime}$ & $\begin{array}{l}\text { Monalisa } \\
\text { Perrone }\end{array}$ & $\begin{array}{l}\text { Caio Coppolla e Augusto } \\
\text { de Arruda Botelho }\end{array}$ \\
\hline 08.06.2020 & $\begin{array}{l}\text { Omitir dados de mortes por } \\
\text { Covid-19 diminui impacto da } \\
\text { doença? }\end{array}$ & $50^{\prime} 20^{\prime \prime}$ & Carol Nogueira & $\begin{array}{l}\text { Gisele Soares e Thiago } \\
\text { Anastácio }\end{array}$ \\
\hline 24.07.2020 & $\begin{array}{l}\text { Falta de coordenação na reabertura } \\
\text { piorou pandemia? }\end{array}$ & $32^{\prime} 19^{\prime \prime}$ & Rafael Colombo & $\begin{array}{l}\text { Veronica Sterman e Gisele } \\
\text { Soares }\end{array}$ \\
\hline 27.07.2020 & $\begin{array}{l}\text { Cancelar eventos de } 2021 \text { é } \\
\text { prematuro? }\end{array}$ & $29^{\prime} 06^{\prime \prime}$ & Rafael Colombo & $\begin{array}{l}\text { Veronica Sterman e Gisele } \\
\text { Soares }\end{array}$ \\
\hline
\end{tabular}

Fonte: elaboração das autoras.

Optamos por tal divisão por corroborarmos o que afirmam Mega e Silva (2019): o jornalismo especializado em saúde caracteriza-se tanto por "divulgar novas pesquisas e desvendar mitos e verdades a respeito de doenças, hábitos pessoais e efeitos de substâncias no organismo" (MEGA; SILVA, 2019, p. 279) quanto por voltar seus esforços para pautas ligadas à gestão sanitária. Entendemos que a divisão, além de permitir uma primeira sistematização de um olhar mais detalhado para o material, também nos abriria espaço para apontar os indícios de legitimidade das fontes acionadas e, consequentemente, verificar os fenômenos comunicativos que caracterizam o manejo da informação científica tratada num espaço de opinião. Acreditamos que, a fim de alcançar os objetivos propostos para o presente trabalho, fez-se necessário considerar as peculiaridades do jornalismo especializado em saúde e o contexto de pandemia provocada pelo novo coronavírus, além das características de cada quadro observado e o exercício dos papéis dos atores participantes de O Grande Debate. Por isso, e retomando a perspectiva foucaultiana (FOUCAULT, 2009) e a discussão de Resende (2014), bem como as contribuições de Miranda (2017), Kuscinsky (2002) e Saint Clair (2012), realizamos a verificação dos 14 vídeos selecionados. Além da catalogação das credenciais dos envolvidos (qualificação e indicação de função em cada vídeo), também observamos o comportamento dos debatedores com relação às fontes (mencionadas ou subentendidas) - este, descrito e registrado a fim de possibilitar a identificação de estratégias e padrões voltados para a indicação da legitimidade e/ou legitimação das fontes. 


\section{RESULTADOS E DISCUSSÕES}

Entre os 14 debates selecionados, sete foram mediados por Monalisa Perrone; quatro, por Reinaldo Gottino; dois por Rafael Colombo; e um por Carol Nogueira. Todos são jornalistas profissionais e, na ocasião da realização de cada debate, todos estavam listados como apresentadores da CNN Brasil. Os debatedores são mencionados como comentaristas.

Dos sete debatedores listados nos vídeos selecionados, cinco são advogados (Gabriela Prioli, Augusto de Arruda Botelho, Gisele Soares, Thiago Anastácio e Veronica Sterman), um é engenheiro civil (André Abduch) e outro é bacharel em direito (Caio Coppolla). As duplas se alternam conforme o tema e dia de realização do debate, mas é possível perceber uma tendência a repetir as duplas, segundo a apresentação dos mediadores, de modo que dois dos comentaristas estão presentes em metade dos vídeos selecionados.

No primeiro grupo de vídeos, na categoria tratamento e cura, detectamos um comportamento compartilhado pelos mediadores: além da apresentação do tema e introdução da discussão, eles tinham a possibilidade de direcionar perguntas para um debatedor a partir das colocações feitas pelo outro, e ainda, de recorrer a imagens (fixas ou referentes às notícias veiculadas) a fim de indicar um tipo de subtema ou desdobramento ligado ao tema principal do debate. Também se manteve constante entre eles o gesto de salientar que as opiniões dos participantes não representavam o posicionamento da emissora, bem como o de ressaltar que, para o telespectador, como mencionado anteriormente, a apresentação de dois pontos de vista opostos sobre o mesmo assunto possibilitaria o desenvolvimento de um ponto de vista próprio.

Já entre os debatedores, percebemos a indicação da mídia (com a citação de reportagens publicadas ou veiculadas sobre o tema), recorrência a estudos científicos, indicação de códigos de ética ou documentos de organização jurídica e orientação de classe como fontes para justificar posicionamentos, ao mesmo tempo em que também detectamos ocorrências de discordâncias desses pontos, conforme as indicações abaixo:

\section{Quadro 3-Comportamento e recorrência às fontes | Categoria tratamento e cura}

\begin{tabular}{|l|l|l|}
\hline Dia & Debatedor 1 & Debatedor $\mathbf{2}$ \\
\hline 19.03.2020 & $\begin{array}{l}\text { Descrição de registros na imprensa; } \\
\text { apontamento de pronunciamentos e notas } \\
\text { oficiais; indicação direta a órgãos da imprensa e } \\
\text { à Organização Mundial da Saúde. }\end{array}$ & $\begin{array}{l}\text { Sem indicação de fontes. Respostas não } \\
\text { referentes ao tema discutido. Crítica à mídia e uso } \\
\text { frequente de expressões como "percebe-se", "eu } \\
\text { tenho a impressão de que", "eu acredito que". }\end{array}$ \\
\hline 07.04.2020 & $\begin{array}{l}\text { Apontamentos de estudos científicos, ocorrências } \\
\text { na imprensa e redes sociais digitais; indicação de } \\
\text { código de ética médica. }\end{array}$ & $\begin{array}{l}\text { Indicação de uma fonte explícita questionada; } \\
\text { alegação de antecipação de estudo científico; } \\
\text { indicação de vídeo de órgão governamental. (Re) } \\
\text { legitimação de fonte. }\end{array}$ \\
\hline 21.05.2020 & $\begin{array}{l}\text { Indicação de organização jurídica e documental } \\
\text { da profissão; indicação de lei. }\end{array}$ & $\begin{array}{l}\text { Indicação de ocorrências veiculadas pela mídia. } \\
\text { Indicação de organização jurídica e documental } \\
\text { da profissão; indicação de orientação de classe } \\
\text { profissional. }\end{array}$ \\
\hline
\end{tabular}

Fonte: elaboração das autoras.

Nessa primeira parte da amostra, já são percebidas características que se repetem nos comportamentos dos debatedores. Há uma tendência à indicação de documentos normativos e/ou regulatórios ou leis, como também instituições como fontes - uma eventual consequência da formação dos debatedores envolvidos. A legitimação dessas fontes segue como que obedecendo a um critério que entendemos como uma série crescente de autorizações, tanto por parte das fontes quanto por parte dos debatedores. Explicamos: no primeiro caso, ao serem apresentadas como documentos ou instituições, essas fontes exercem um espaço de autoridade e são apontadas como organizadoras de um recorte específico do tema tratado, a fim de 
referendar as falas dos comentaristas; no segundo caso, os participantes do debate fortalecem a legitimidade das fontes invocadas a partir de suas posições (reforçadas por suas credenciais somadas a suas presenças no quadro, portanto alçadas momentaneamente a autoridades capazes de invocar fontes legítimas).

A mídia, amplamente explorada em nossa discussão teórica como dependente das fontes para a produção de notícias, é usada como uma fonte para os debatedores. Neste caso também se faz presente a legitimação operada no sentido comentarista - fonte, mas abre-se espaço para um outro movimento: a autolegitimação, ainda mais forte que a anterior. Isso porque a mídia como instituição legitimadora termina por reforçar suas próprias ocorrências, apoiada no uso de imagens e citação de publicações/veiculações.

Porfim,tambémpercebemosum outro movimento: umtipo de(re)legitimação dafonte, assim denominado por compreender o movimento de apresentação da fonte por um dos debatedores (contemplando, portanto, o movimento de legitimação ao qual já nos referimos), seguido por sua invalidação (por um debatedor ou pelo mediador, ao apontar inveracidade ou inconsistência,apoiado em fontes midiáticas ou documentais), mas sem resultar em sua eliminação das fontes de informação em que se baseiam os argumentos do debatedor que a apresentou.

Já no segundo grupo de vídeos, selecionados sob a categoria controle social, percebemos um comportamento parecido entre os moderadores. Introduzido o assunto principal, todos fizeram a transição de um tema para outro, quando o debate comportasse mais de um assunto, e de um subtema para outro subtema, fazendo uso de comentários ou inserções curtas de trechos de reportagens a fim de introduzir alguma pergunta. Todos ressaltaram, também, que o quadro proporcionava visões diferentes sobre um mesmo assunto e que as opiniões dos comentaristas não refletiam a opinião da CNN Brasil.

Entre os debatedores, também encontramos inicialmente algumas similaridades no ocorrido com o grupo anterior: a mídia foi apontada como fonte em diferentes ocasiões, bem como a indicação de pesquisas e instâncias jurídicas, além de órgãos oficiais, governamentais ou de classe, como é possível observar a seguir:

\section{Quadro 4-Comportamento e recorrência às fontes | Categoria controle social}

(continua)

\begin{tabular}{|l|l|l|}
\hline Dia & Debatedor 1 & Debatedor 2 \\
\hline 20.03.2020 & $\begin{array}{l}\text { Menção de pronunciamentos oficiais de } \\
\text { autoridades políticas e jurídicas; indicação de } \\
\text { ocorrências veiculadas pela mídia; descrição de } \\
\text { leis e documentos oficiais; questionamento de } \\
\text { fonte apresentada pelo oponente. }\end{array}$ & $\begin{array}{l}\text { Indicação de decisões de órgãos públicos; } \\
\text { mença de pronunciamentos de autoridades; } \\
\text { apresentação direta de fonte inconsistente; uso } \\
\text { de generalização de fontes, com expressões } \\
\text { como "o povo brasileiro" e "pessoas de bem". }\end{array}$ \\
\hline 26.03.2020 & $\begin{array}{l}\text { Indicação de ocorrências veiculadas pela mídia; } \\
\text { citação de especialistas e menção a revistas } \\
\text { especializadas; citação de falas de autoridades. }\end{array}$ & $\begin{array}{l}\text { Indicação de ocorrências veiculadas pela mídia; } \\
\text { citação de especialistas e de autoridades. Uso } \\
\text { de generalização de fontes com expressões } \\
\text { como "tenho fonte segura", "estudos do mundo } \\
\text { todo" e "o povo brasileiro". }\end{array}$ \\
\hline 14.04 .2020 & $\begin{array}{l}\text { Apontamento de lei e citações de entidades } \\
\text { internacionais; indicação de documento oficial } \\
\text { e decisão de órgãos nacionais; identificação de } \\
\text { fonte ligada a parte do governo federal. }\end{array}$ & $\begin{array}{l}\text { Indicação de citação pública e notória, mas } \\
\text { sem citar diretamente a fonte; citações de } \\
\text { autoridades veiculadas pela mídia. }\end{array}$ \\
\hline 17.04.2020 & $\begin{array}{l}\text { Citação de pronunciamento oficial; indicação de } \\
\text { ocorrências veiculadas pela mídia; apresentação } \\
\text { de fonte questionada. (Re)legitimação de fonte. }\end{array}$ & $\begin{array}{l}\text { Citação de estudos publicados; indicação de } \\
\text { dados oficiais; indicação de nomes e citação } \\
\text { de pesquisadores. Questionamento de fonte } \\
\text { apresentada pelo outro debatedor. }\end{array}$ \\
\hline 04.05.2020 & $\begin{array}{l}\text { Indicação de ocorrências veiculadas pela mídia; } \\
\text { citação de leis; generalizaça/indefinição de } \\
\text { fontes, com o uso de expressões como "alguns". }\end{array}$ & $\begin{array}{l}\text { Indicação de manifestações de entidade } \\
\text { internacional; indicação de ocorrências } \\
\text { veiculadas pela mídia; generalização de fontes. }\end{array}$ \\
\hline
\end{tabular}




\begin{tabular}{|c|c|c|}
\hline Dia & Debatedor 1 & Debatedor 2 \\
\hline 06.05.2020 & $\begin{array}{l}\text { Indicação de ocorrências veiculadas pela } \\
\text { mídia; citação de falas de autoridades; citação } \\
\text { de determinação de órgão governamental; } \\
\text { indicação de organizações coletivas. }\end{array}$ & $\begin{array}{l}\text { Citação de lei e instrumentos jurídicos; } \\
\text { generalização de fontes. }\end{array}$ \\
\hline 19.05.2020 & $\begin{array}{l}\text { Indicação de dados emitidos por órgãos oficiais; } \\
\text { citação de pesquisas e dados mencionados por } \\
\text { autoridades. Generalização de fontes. }\end{array}$ & $\begin{array}{l}\text { Indicação de ocorrências veiculadas pela mídia; } \\
\text { citação de falas de autoridades e de órgãos } \\
\text { governamentais; citação de lei. Generalização } \\
\text { de fontes. }\end{array}$ \\
\hline 03.06 .2020 & $\begin{array}{l}\text { Indicação de citações públicas de autoridades; } \\
\text { indicação de ocorrências veiculadas pela } \\
\text { mídia; citação de pesquisa desenvolvida } \\
\text { por organização; citação de pesquisas } \\
\text { desenvolvidas por coletivos de pesquisadores. }\end{array}$ & $\begin{array}{l}\text { Indicação de ocorrências veiculadas pela mídia; } \\
\text { citação de autoridades e de dados informados } \\
\text { por entidades internacionais; generalização de } \\
\text { fontes e sentenças. }\end{array}$ \\
\hline 08.06 .2020 & $\begin{array}{l}\text { Indicação de citações de autoridades; indicação } \\
\text { de ocorrências veiculadas pela mídia; citação de } \\
\text { recomendações de organizações internacionais. }\end{array}$ & $\begin{array}{l}\text { Citação de manifestações oficiais de órgãos } \\
\text { e de entidades representativas; indicação de } \\
\text { ocorrências veiculadas pela mídia. }\end{array}$ \\
\hline 24.07.2020 & $\begin{array}{l}\text { Indicação de dados oficiais; menção de órgãos } \\
\text { de controle e de representação de classe; } \\
\text { indicação de ocorrências veiculadas pela mídia. } \\
\text { Generalização de fontes. }\end{array}$ & $\begin{array}{l}\text { Indicação de citações de autoridades; indicação } \\
\text { de dados oficiais; citação de lei. Generalização } \\
\text { de fontes. }\end{array}$ \\
\hline 27.07.2020 & $\begin{array}{l}\text { Citação de autoridades; indicação de } \\
\text { ocorrências veiculadas pela mídia; citação de } \\
\text { falas de personalidades públicas. }\end{array}$ & $\begin{array}{l}\text { Indicação de ocorrências veiculadas pela mídia; } \\
\text { citação de leis e medidas jurídicas; indicação } \\
\text { de estudos cuja realização futura foi anunciada. } \\
\text { Generalização de fontes. }\end{array}$ \\
\hline
\end{tabular}

Fonte: elaboração das autoras.

Tal como na anterior, nesta parte da amostra, é possível perceber a tendência à repetição de um tipo de padrão de recursos dos quais os comentaristas se valem para fortalecer seus argumentos e/ou opiniões. Ao mesmo tempo que se mantém uma forte presença da indicação de documentos regulatórios, leis e mecanismos jurídicos como fontes das colocações apresentadas pelos debatedores, estes também aparecem acompanhados agora pela indicação ou citação explícita de seus operadores. A segunda categoria ainda nos permitiu verificar um maior protagonismo das falas de autoridades e representantes de entidades, ao lado dos já detectados órgãos oficiais e organizações específicas.

Também aqui reforçamos o que foi apontado anteriormente como a sequência de autorizações legitimadoras das fontes apresentadas, das quais participam tanto a autoridade própria de cada fonte (seja por se tratar de um órgão ou de um representante de um órgão ou entidade) quanto os debatedores. A mídia como fonte dos comentaristas também se mantém como uma presença frequente nas indicações dos participantes, autolegitimando-se como fonte e fomentando uma perspectiva de veracidade, a fim de reforçar as colocações levantadas pelos participantes do debate.

Por fim, a (re)legitimação também foi detectada na amostra referente à segunda categoria, com a ocorrência de invalidação de uma fonte seguida de sua permanência entre os argumentos elencados pelo debatedor que a apresentou primeiro. No entanto, esse movimento não foi o único registrado quando observamos o comportamento dos comentaristas e suas referências às fontes.

Outros dois movimentos detectados foram os que denominamos de indefinição e de generalização. No primeiro caso, os debatedores fazem referência a uma fonte abstrata, caracterizada por uma menção que indefine sua identidade: 'algumas pessoas', 'alguns representantes', 'algumas entidades', por exemplo, são 
os tipos de expressões utilizadas nessas circunstâncias. Já no segundo caso, os debatedores fazem referência a uma pretensa fonte igualmente abstrata, mas cuja identidade não é apenas definida como também é necessariamente coletiva: 'as pessoas de bem', 'o povo', 'a população', 'os políticos', 'os profissionais da saúde' estão entre os exemplos de expressões usadas nesses momentos.

No caso desses dois movimentos, o comentarista ganha uma margem de espaço para declarar sua opinião/argumento sem, todavia, especificar diretamente a fonte (personificada em indivíduos ou materializada em iniciativas de pesquisa ou em documentos). Ao mesmo tempo, esse artifício tem como princípio permitir que sua fala seja legitimada por uma fonte, ainda que esta esteja localizada num plano abstrato. Diante de nossas observações e dos resultados percebidos, chamamos estas de pseudofontes ou fontes falsas, que diferem das fontes (re)legitimadas por seu caráter abstrato e sua permanência não questionada na fala do debatedor.

Nos vídeos selecionados para as duas categorias, percebemos ainda a consciência dos comentaristas sobre o peso das fontes para suas afirmações. Em diferentes momentos, a alegação de que as informações eram pretensamente trazidas em primeira mão, colhidas em conversa privada direta com algum representante de órgão governamental ou instituição, pontuou a fala dos participantes, novamente num esforço de legitimação da própria fala. Essa percepção nos permitiu constatar, assim, a posição dos debatedores como fontes para o público, constatação ressaltada pela repetição, em diferentes momentos, das alegações feitas por eles de que eram comprometidos com 'a verdade dos fatos'.

Os resultados obtidos estão alinhados com Saint Clair (2012) e sua reflexão sobre a abordagem da saúde no jornalismo: o fato de o produto jornalístico não estar vinculado a uma verdade específica defendida pela ciência "[...] não significa que a imprensa não corrobore o princípio de que o 'lugar privilegiado de produção de verdades' na atualidade seja o domínio científico." (SAINT CLAIR, 2012, p. 177) Ainda considerando os resultados encontrados e o debate de opiniões sobre saúde, percebemos também que a adoção das estratégias de legitimação das fontes exercitadas pelos comentaristas tornam complexa a identificação do lugar do conhecimento científico e borram fronteiras entre fatos, opiniões e estratégias argumentativas momentâneas. Tal como nos garante o autor, "[...] há aqui uma região especial da opinião que é irredutível tanto à verdade quanto a uma espécie de senso comum generalizado.” (SAINT CLAIR, 2012, p. 177)

$\mathrm{O}$ todo analisado nas duas categorias aponta um conjunto complexo que resulta no deslocamento no manejo da informação científica referente à pandemia provocada pelo novo coronavírus. Este deslocamento não se refere a uma mudança paradigmática do entendimento social da importância da informação científica, no sentido de proporcionar uma desconsideração deliberada de sua validade ou de sua existência (enquanto balizador de medidas voltadas tanto para o controle social quanto para o tratamento e cura da Covid-19 e seus reflexos), mas sim a uma mudança de validação de fluxos da informação científica.

A divulgação científica, valiosa aliada na popularização de processos, conceitos e fenômenos, não é dependente de uma única categoria de divulgadores. No entanto, depende necessariamente de um ponto de partida, que é a fonte da informação. Podemos dizer que, de praxe, idealmente e descrito de forma simples, o fluxo da informação científica é atravessado pela seguinte sequência: 1) pesquisador/pesquisa (fonte); 2) divulgador científico; 3) adequação e/ou simplificação da linguagem para ampliação do público capaz de consumir a informação; 4) veiculação da informação; 5) público.

Por outro lado, a possibilidade de apropriação temática não implica, necessariamente, que ela se apoia na divulgação científica. A ascensão da pandemia provocada pelo novo coronavírus enquanto temática e cenário da prática da comunicação científica parece reforçar um ambiente tal, capaz de permitir adaptações e apropriações que, no caso do quadro analisado, refletem uma sistematização que considera quatro instâncias: 
a) cenário de partida: que pode ser entendido como um tipo de fator condicionante inicial. Enquanto formato de um debate dentro de um programa jornalístico, as marcas deixadas em todas as edições do quadro analisado, nas introduções feitas pelos apresentadores, enfatizam que se trata de um espaço em que pontos de vista diversos são confrontados a fim de que o telespectador possa construir sua opinião de modo independente, ao mesmo tempo em que o tema principal (diretamente ligado à pandemia causada pelo novo coronavírus) é declarado, reforçado e detalhado em sua proposta;

b) ponto de apoio: o recurso às fontes que exercem a função de garantia. As fontes, independentemente de sua referência ou origem, são apresentadas no intuito de reforçar a validade dos argumentos apresentados pelos debatedores. Todas, por serem inseridas nas argumentações dos comentaristas, gozam das mesmas condições ambientais e momentâneas de credibilidade. É a primeira condição para o deslocamento da validação dos fluxos de informação científica;

c) ponto de tensão: entendido como a manutenção das fontes no confronto de argumentos dos comentaristas, desconsideradas suas condições de legitimidade. Aqui, o deslocamento ganha força, materializada na referência às fontes ligadas a instâncias não científicas e na manutenção de pseudofontes em contraposição às fontes de informações científicas acionadas pelos comentaristas para discutir detalhes ligados ao tema do debate;

d) ponto de chegada: caracterizado pela simplificação da linguagem e a incorporação do papel de agente da informação pelos comentaristas. Nesta última instância, os debatedores se colocam como garantidores da validade da informação, por apresentarem fontes - que, por sua vez, têm o papel de validar o argumento apresentado. Aqui, o deslocamento se consolida: a legitimidade da fonte é secundarizada em favor de sua exposição midiática. Ou seja: o tema se sobrepõe às fontes.

Estas quatro instâncias de sistematização refletem pontos de tensionamento no manejo da informação científica em quadro jornalístico-opinativo referente à pandemia causada pelo novo coronavírus. Diante de todo o exposto, nos encaminhamos agora para a finalização de nosso trabalho.

\section{CONSIDERAÇÕES FINAIS}

No presente artigo, nos preocupamos em refletir sobre as fontes num ambiente de debate de opiniões, considerando questões que permeiam o cenário de nossa discussão: a abordagem da saúde pelo jornalismo, a objetividade jornalística como argumento de profissionalismo, a vontade da verdade como legitimadora do papel e uso da fonte assim como a espetacularização como condições que perpassam o debate propriamente dito. Encontramos em nosso percurso um cenário que se opunha a um jornalismo idealizado, que entende como sinônimos a imparcialidade e a qualidade.

Nossa jornada também nos permitiu perceber uma inversão da noção de objetividade entendida tanto como neutralidade quanto como metodologia profissional, ainda que num espaço voltado francamente para a manifestação opinativa. O jornalista-mediador, embora obedecendo um protocolo metodológico na condução do debate, fica numa faixa fora do alcance das marcas nas quais se apoia a noção de isenção, uma vez que acaba tomando por base as colocações dos debatedores para conduzir o quadro. Os debatedores valem-se, ao mesmo tempo, de fontes institucionais e/ou oficiais, e da própria mídia como fonte, bem como de pseudofontes.

Curiosamente, todas as fontes são submetidas ao procedimento de legitimação ou deslegitimação no momento do debate, mas o contexto de espetacularização nos proporciona outros fenômenos, que apontamos como (re)legitimação, indefinição e generalização. Esta última aponta para uma preocupante questão: uma potencial irrelevância do processo de apuração e a naturalização da veiculação midiática de material não checado, sob o argumento de que a responsabilidade do que é dito é do comentarista/ debatedor e não do veículo. 
As condições de legitimidade e legitimação das fontes acionadas pelos comentaristas em O Grande Debate denunciam, apontamos anteriormente, um deslocamento de validação no fluxo de informação científica ao atravessar quatro instâncias que resultam na legitimidade da fonte secundarizada em favor da exposição midiática. Este quadro se mostra especialmente relevante no contexto pandêmico de sua realização: uma vez que os fenômenos de legitimação, deslegitimação, (re)legitimação, indefinição e generalização permeiam o manejo da informação científica, esta protagoniza um duplo paradoxo ao ser reconhecida como o tipo de informação que não se deve ignorar mas é abordada sob perspectivas que podem dissociar legitimidade da fonte da informação científica. Consideramos que a pandemia à qual nos referimos foi um elemento potencializador de tais fenômenos, num movimento contributivo para a constituição de uma infodemia cujos reflexos extrapolam o quadro analisado e alcançam mediações comunicativas que permeiam os processos coletivos de prevenção, cuidado e cura da Covid-19.

As diferentes áreas de atuação dos comentaristas mobilizados para as edições observadas de O Grande Debate nos parecem indícios de pontos que merecem atenção em estudos futuros, uma vez que os efeitos de suas atuações podem contribuir para reflexões ainda mais detalhadas sobre o manejo da informação científica enquanto parte integrante de fenômeno comunicativo característico proporcionado pela abordagem midiática da pandemia causada pelo novo coronavírus.

Por fim, entendemos que, no que se refere ao corpus analisado, a espetacularização da polarização opinativa proporcionou muito mais uma equiparação entre opinião, fato e inverdades - algo que consideramos especialmente perigoso para a abordagem da saúde pelo jornalismo, pois apoia-se no borramento de fronteiras entre os três itens mencionados que deveriam ser fortemente demarcadas não só, mas principalmente, num contexto pandêmico. Acreditamos que, em circunstâncias nas quais é mantida a legitimidade da fonte potencialmente superada pela legitimidade midiática, abre-se um caminho cujo desdobramento pode indicar reflexões que se debrucem sobre a ética jornalística e seus reflexos em processos de descolamento de responsabilidades entre o jornalista, sua fonte e as informações prestadas por ela.

\section{REFERÊNCIAS}

ALSINA, Miquel Rodrigo. A construção da notícia. Petrópolis: Vozes, 2009.

BRASIL. Ministério da Saúde. O que é Covid-19. Brasília, DF: O Ministério, c2020. Disponível em: https:// coronavirus.saude.gov.br/sobre-a-doenca\#o-que-e-covid. Acesso em: 5 set. 2020.

CARVALHO, Rafiza Luziani Varão Ribeiro. Notícias falsas ou propaganda?: Uma análise do estado da arte do conceito de fake news. Questões Transversais, São Leopoldo, v. 7, n. 13, p. 21-30, jan.-jun. 2019. Disponível em: http://revistas.unisinos.br/index.php/questoes/article/view/19177/PDF. Acesso em: 15 abr. 2020.

CHAPARRO, Manuel Carlos. Jornalismo: linguagem dos conflitos. São Paulo: Edições Chaparro, 2014.

CHAPARRO, Manuel Carlos. Pragmática do jornalismo: buscas práticas para uma teoria da ação jornalística. São Paulo: Summus Editorial, 1994.

CNN BRASIL. Sobre a CNN Brasil. São Paulo: CNN Brasil, c2020. Disponível em: https://www.cnnbrasil. com.br/mais/sobre-a-cnn. Acesso em 20 ago. 2020.

DEBORD, Guy. A sociedade do espectáculo. Lisboa: Edições Antipáticas, 2005.

ERBOLATO, Mário L. Técnicas de codificação em jornalismo. 5. ed. São Paulo: Ática, 2008.

FERNANDES, Eduardo Georjão. Contradições da prática jornalística: entre a (persistente ideia de "objetividade" e a "construção social da notícia". Revista Contraponto, Porto Alegre, v. 3, n. 1, p. 135-150, jun. 2016. Disponível em: https://seer.ufrgs.br/contraponto/article/view/65739/37773. Acesso em: 25 jul. 2020.

FOUCAULT, Michel. A ordem do discurso. 19. ed. São Paulo: Edições Loyola, 2009. 
FREITAS, Ananias José de; PIRES Teresinha Maria de C. Cruz. Produção da opinião jornalística na berlinda. Líbero, São Paulo, v. 12, n. 23, p. 129-141, jun. 2009. Disponível em: http://seer.casperlibero.edu.br/index. php/libero/article/view/538/512. Acesso em: 1 ago. 2020.

HALL, Stuart; CHRITCHER Chas; JEFFERSON, Tony; CLARKE, John; ROBERTS, Brian. A produção social das notícias: o mugging nos media. In: TRAQUINA, Nelson (org.). Jornalismo: questões, teorias e estórias. Lisboa: Editora Vega, 1993, p. 224-248.

JORGE, Thaïs de Mendonça. Notícia e fake news: uma reflexão sobre dois aspectos do mesmo fenômeno da mutação, aplicada ao jornalismo contemporâneo. Revista Latino-americana de Jornalismo Âncora, João Pessoa, v. 4, n. 2, jul.-dez. 2017, p. 57-73. DOI: https://doi.org/10.22478/ufpb.2359-375X.2017v4n2.40094. Disponível em: https://periodicos.ufpb.br/index.php/ancora/article/view/40094. Acesso em: 16 abr. 2020.

KUSCINSKY, Bernardo. Jornalismo e saúde na era neoliberal. Saúde e Sociedade, São Paulo, v. 11, n. 1, p. 95-103, jul. 2002. DOI: https://doi.org/10.1590/S0104-12902002000100010. Disponível em: https://www. scielo.br/j/sausoc/a/kFWHCw7rqJCmkyQjZFf3DfP/?lang=pt. Acesso em: 16 out. 2020.

LAGE, Nilson. A reportagem: teoria e prática da entrevista e pesquisa jornalística. 5. ed. Rio de Janeiro: Record, 2005.

LEAL, Bruno Souza; CARVALHO Carlos Alberto. De fontes a agentes jornalísticos: a crítica de uma metáfora morta. Intexto, Porto Alegre, n. 34, set.-dez. 2015, p. 606-622. Disponível em: https://doi.org/10.19132/18078583201534.606-622. Acesso em: 23 jul. 2020.

MAIA, Kênia Beatriz Ferreira; GOMES, Ana Cecília Aragão. Para pensar o fazer e a pesquisa em divulgação científica e jornalismo científico. In: CONGRESSO BRASILEIRO DE CIÊNCIAS DA COMUNICAÇÃO, 29., set. 2006, Brasília, DF. Anais [...]. São Paulo: Intercom, 2006, p. 1-14.

MEGA Helena; SILVA, André Chaves de Melo. Ciência, jornalismo e saúde: a judicialização em pauta. Extraprensa, São Paulo, v. 13, n. 1, p. 277-291, jul.-dez. 2019. Disponível em: https://doi.org/10.11606/ extraprensa2019.164114. Acesso em: 17 out. 2020.

MELKI, Mickael; PICKERING, Andrew. Ideological polarization and the media. Economic Letters, [s. I.], v. 125, n. 1, p. 36-39, out. 2014. Disponível em: https://doi.org/10.1016/j.econlet.2014.08.008. Acesso em: 15 ago. 2020.

MELO, José Marques de. Jornalismo opinativo: gêneros opinativos no jornalismo brasileiro. 3. ed. Campos do Jordão: Editora Mantiqueira, 2003.

MELO, José Marques de. Panorama diacrônico dos gêneros jornalísticos. In: CONGRESSO BRASILEIRO DE CIÊNCIAS DA COMUNICAÇÃO, 23., set. 2010, Caxias do Sul. Anais [...]. São Paulo: Intercom, 2010. p.1-8.

MELO, José Marques de; ASSIS, Francisco de. Gêneros e formatos jornalísticos: um modelo classificatório. Intercom - Revista Brasileira de Ciência da Comunicação, São Paulo, v. 39, n. 1, p. 39-56, jan.-abr. 2016. Disponível em: http://portcom.intercom.org.br/revistas/index.php/revistaintercom/article/view/2354/1965. Acesso em: 2 ago. 2020.

MIGUEL, Luis Felipe. Jornalismo, polarização política e a querela das fake news. Estudos em Jornalismo e Mídia, Florianópolis, v. 16, n. 2, p. 46-58, jul.-dez. 2019. Disponível em: https://periodicos.ufsc.br/index.php/ jornalismo/article/view/1984-6924.2019v16n2p46. Acesso em 2 ago. 2020.

MIRANDA, Amanda Souza de. O saber médico e o jornalismo especializado em saúde: como uma epidemia se torna notícia. Revista Eletrônica de Comunicação, Informação \& Inovação em Saúde, Rio de Janeiro, v. 11, n. 2, p. 1-13, abr.-jun. 2017. DOI: https://doi.org/10.29397/reciis.v11i2.1291. Disponível em: https://www. reciis.icict.fiocruz.br/index.php/reciis/article/view/1291. Acesso em: 18 out. 2020.

NEVEU, Erik. Sociologia do jornalismo. São Paulo: Edições Loyola, 2006.

ORGANIZAÇÃO PAN-AMERICANA DA SAÚDE (OPAS). Folha informativa COVID-19. Brasília, DF: Opas, c2020. Disponível em: https://www.paho.org/pt/covid19. Acesso em: 5 set. 2020.

PAULA, Lorena Tavares de; SILVA, Thiago dos Reis Soares da; BLANCO, Yuri Augusto. Pós-verdade e fontes de informação: um estudo sobre fakenews. Revista Conhecimento em Ação, Rio de Janeiro, v. 3, n. 1, p. 93-110, jan.-jun. 2018. DOI: https://doi.org/10.47681/rca.v3i1.18084. Disponível em: https://revistas.ufrj.br/ index.php/rca/article/view/16764/11221. Acesso em: 13 abr. 2020. 
PENA, Felipe. Teoria do jornalismo. 3. ed. São Paulo: Contexto, 2012.

PINTO, Manuel. Fontes jornalísticas: contributos para o mapeamento do campo. Comunicação e Sociedade, Braga, v. 2, n. 1, p. 277-294, ago. 2000. DOI: https://doi.org/10.17231/comsoc.2(2000).1401. Disponível em: https://revistacomsoc.pt/index.php/revistacomsoc/article/view/830. Acesso em: 23 maio 2019.

RESENDE, Fernando. Representação das diferenças no discurso jornalístico. Brazilian Journalism

Research, Brasília, DF, v. 10, n. 2, p. 206-223, dez. 2014. DOI: http://doi.org/10.25200/BJR.v10n2.2014.749. Disponível em: https://bjr.sbpjor.org.br/bjr/article/view/749. Acesso em: 8 ago. 2019.

SAINT CLAIR, Ericson. A depressão como objeto jornalístico: explorando o arquivo do Grupo Folha (19702009). Brazilian Journalism Research, Brasília, DF, v. 8, n. 1, p. 166-181, 2012. Disponível em: https://doi. org/10.25200/BJR.v8n1.2012.323. Acesso em: 16. out. 2020.

SCHMITZ, Aldo Antonio. Fontes de notícias: ações e estratégias das fontes no jornalismo. Florianópolis: Combook, 2011.

SPONHOLZ, Liriam. As objetividades do jornalista brasileiro. Líbero, São Paulo, a. 6, n. 21, jun. 2008, p. 6977. Disponível em: http://seer.casperlibero.edu.br/index.php/libero/article/view/602/570. Acesso em: 25 jul. 2020.

TUCHMAN, Gaye. A objectividade como ritual estratégico: uma análise das noções de objectividade dos jornalistas. In: TRAQUINA, Nelson (org.). Jornalismo: questões, teorias e estórias. Lisboa: Editora Vega, 1993. p. 74-90. 